\title{
Protective effect of eNOS overexpression against ischemia/reperfusion injury in small-for-size liver transplantation
}

\author{
BO ZHANG $^{1 *}$, QIU-HUA LIU ${ }^{1 *}$, CUI-JIE ZHOU ${ }^{1}$, MING-ZHENG HU $^{2}$ and HAI-XIN QIAN ${ }^{1}$ \\ ${ }^{1}$ Department of General Surgery, Zhangjiagang Hospital Affiliated to Soochow University, Zhangjiagang, Jiangsu 215600; \\ ${ }^{2}$ Institute of Hepatopancreatobiliary Surgery, Yichang Central People's Hospital, \\ China Three Gorges University, Yichang, Hubei 443003, P.R. China
}

Received July 2, 2015; Accepted August 25, 2015

DOI: $10.3892 / \mathrm{etm} .2016 .3762$

\begin{abstract}
Ischemia/reperfusion (I/R) injury can occur during small-for-size liver transplantation, resulting in delayed graft function and decreased long-term graft survival. The aim of the present study was to evaluate the effects of genetic overexpression of endothelial nitric oxide synthase (eNOS) in protecting hepatocytes against I/R injury in a rat model of small-for-size liver transplantation. L02 liver cells were transfected with the eNOS gene using an adenovirus (Ad-eNOS). eNOS expression was detected using quantitative polymerase chain reaction and western blot analysis. To evaluate the effect of eNOS overexpression, L02 cells were placed in a hypoxic environment for $12 \mathrm{~h}$ and immediately transferred to an oxygen-enriched atmosphere. For in vivo testing, rats pretreated with Ad-eNOS or control underwent small-for-size liver transplantation. At $6 \mathrm{~h}$ after reperfusion, the bile quantity, serum transaminase and nitric oxide (NO) levels, and histological outcomes were evaluated. Cell apoptosis was assessed by flow cytometry or TUNEL assay. In vitro, Ad-eNOS prevented apoptosis in L02 cells with an increase in the level of NO in culture supernatant. In vivo, Ad-eNOS pre-treatment significantly increased bile production, improved abnormal transaminase levels, diminished apoptosis among liver cells, and decreased hepatocellular damage at $6 \mathrm{~h}$ after I/R injury. The eNOS-mediated renal protective effects might be associated with the downregulation of tumor necrosis factor- $\alpha$ and a reduction in macrophage
\end{abstract}

Correspondence to: Dr Cui-Jie Zhou, Department of General Surgery, Zhangjiagang Hospital Affiliated to Soochow University, 68 Jiyang West Road, Zhangjiagang, Jiangsu 215600, P.R. China E-mail: zcj158158@126.com

Dr Ming-Zheng Hu, Institute of Hepatopancreatobiliary Surgery, Yichang Central People's Hospital, China Three Gorges University, 183 Yiling Road, Yichang, Hubei 443003, P.R. China

E-mail: hmz08@sina.com

\section{${ }^{*}$ Contributed equally}

Key words: ischemia reperfusion injury, liver transplantation, nitric oxide, nitric oxide synthase activation in the early stage of reperfusion in small-for-size liver allografts. eNOS-derived NO production significantly attenuates hepatic I/R injury. Thus, eNOS overexpression constitutes a promising therapeutic approach to prevent liver I/R injury following small-for-size liver transplantation.

\section{Introduction}

Liver transplantation has been shown to be the only effective therapy for patients with end-stage liver disease (1). A small-for-size liver graft is defined as a graft involving $<40 \%$ of the standard liver volume or a graft to recipient weight ratio of $0.8-1.0 \%$ (2). In recent years, the demand for partial liver grafts from either deceased or living donors has been increasing worldwide, due to the severe shortage of donor organs (3). However, recent studies reported that small-for-size liver grafts are associated with serious complications and graft failure $(4,5)$.

Multiple factors, including transient portal hypertension, ischemia/reperfusion (I/R) injury and subsequent severe inflammatory responses in the early phase of reperfusion after small-for-size liver transplantation may result in graft failure (6). Among these, I/R injury severely damages the transplanted liver following temporary clamping of the hepatoduodenal ligament during liver transplantation (7). I/R injury involves the initial tissue damage caused by deprivation of blood flow and oxygen and additional damage caused by the return of the blood supply during reperfusion (8). The mechanisms underlying I/R injury are complex and involve endothelial cell adhesion, increased neutrophil infiltration, release of pro-inflammatory cytokines, as well as the generation of reactive oxygen species (ROS) and reactive nitrogen species (9). The classical markers used to assess the severity of hepatic I/R injury include abnormal liver enzyme levels as well as histological signs of tissue damage (10). Considering the serious and unavoidable damage caused by I/R injury to grafts, effective therapeutic strategies aimed at attenuating I/R injury and reducing the death of hepatocytes would be of great benefit $(11,12)$.

Nitric oxide (NO) is synthesized from the amino acid L-arginine by the action of NO synthase (NOS) and plays an important role in the regulation of renal vascular tone and hemodynamics $(13,14)$. Three NOS isoforms exist: Endothelial NOS (eNOS), neuronal NOS and inducible NOS (iNOS) (13). 
Excessive levels of iNOS-derived NO production may be involved in the inflammatory process and promote I/R injury (15). However, low levels of NO produced at by eNOS physiologically regulate normal vascular tone within the sinusoids, prevent leukocyte adhesion and limit ROS production, thus exerting a beneficial effect on I/R injury (16).

To date, no study has provided direct evidence regarding whether delivery of exogenous eNOS via an adenoviral (Ad) vector is cytoprotective against hepatic I/R injury in the context of small-for-size liver transplantation. To confirm this, we evaluated the effects of genetic overexpression of eNOS in the protection of hepatocytes against I/R injury in a rat model of small-for-size liver transplantation.

\section{Materials and methods}

Ad vector and transfection. The Ad-vector and Ad-eNOS were obtained from the Second Military Medical University (Shanghai, China). Ad-eNOS was further amplified in HEK293 cells (Biolef, Shanghai, China). Viral particles were purified using cesium chloride density gradient centrifugation. HEK293 cells in serum-free Dulbecco's modified Eagle's medium (DMEM; Gibco; Thermo Fisher Scientific, Inc., Grand Island, NY, USA) were transfected with Ad-eNOS to identify the optimal conditions. The Ad-eNOS was applied with a titer of $9.35 \times 10^{9} \mathrm{PFU} / \mathrm{ml}$. L02 cells were transfected with Ad-eNOS in a humidified atmosphere containing $5 \% \mathrm{CO}_{2}$ at $37^{\circ} \mathrm{C}$. Transfection with an empty Ad-vector (Ad-null) served as a control. The cells were harvested $48 \mathrm{~h}$ after transfection for analysis.

In vitro culture. The human normal liver cell line L02 was obtained from the Shanghai Institute of Biochemistry and Cell Biology (Shanghai, China). The cells were grown in Roswell Park Memorial Institute-1640 medium supplemented with 10\% fetal bovine serum (Gibco; Thermo Fisher Scientific, Inc.) and cultured in a humidified atmosphere containing $5 \% \mathrm{CO}_{2}$ at $37^{\circ} \mathrm{C}$.

L02 cells were transferred to 24 -well plates at a density of $3.6 \times 10^{4}$ cells per well. Three groups (six wells per group) were established: Experimental, control and normal groups. Ad-eNOS (5x10 6 PFU) was added to the cells in the experimental group, whereas Ad-null was added in the control and normal groups. Then the cells in the experimental and control groups were placed in a hypoxic environment $\left(95 \% \mathrm{~N}_{2}\right.$ and $5 \%$ $\mathrm{CO}_{2} ; \mathrm{PO}_{2}, \leq 4 \mathrm{kPa}$ ) for $12 \mathrm{~h}$. After replacement of the medium with fresh culture medium, the cells were moved to an oxygen enriched atmosphere $\left(85 \% \mathrm{O}_{2}\right.$ and $\left.15 \% \mathrm{CO}_{2} ; \mathrm{PO}_{2}, \geq 13 \mathrm{kPa}\right)$ for another $12 \mathrm{~h}$. The cells in the normal group were cultured in a normal atmosphere containing $5 \% \mathrm{CO}_{2}$ at $37^{\circ} \mathrm{C}$.

Reverse transcription-quantitative polymerase chain reaction $(R T-q P C R)$. Total RNA was extracted from cultured cells or liver tissues using TRIzol reagent (Gibco; Thermo Fisher Scientific, Inc.), and DNase was used to treat genomic DNA prior to RT. Total RNA (500 ng) was reverse transcribed into cDNA using a Prime-Script RT kit (Takara Bio, Inc., Otsu, Japan), according to the manufacturer's instructions. The sequences of the primers used (Takara Bio, Inc.) were as follows: eNOS, forward 5'-TCA GTGGCTGGTACATGAGC-3' and reverse 5'-TATCCAGGT CCATGCAGACA-3'; GAPDH, forward 5'-ACTGGAACG GTGAAGGTGAC-3' and reverse 5'-AGAGAAGTGGGGTGG
CTTTT-3'. DNA amplification was performed in a PCR system thermocycler (Biometra GmbH, Göttingen, Germany) using the following conditions: Initial denaturation step at $95^{\circ} \mathrm{C}$ for $5 \mathrm{~min}$, followed by 35 cycles of $95^{\circ} \mathrm{C}$ for $15 \mathrm{sec}, 60^{\circ} \mathrm{C}$ for $30 \mathrm{sec}$, and $72^{\circ} \mathrm{C}$ for $30 \mathrm{sec}$, and a final extension phase at $72^{\circ} \mathrm{C}$ for $10 \mathrm{~min}$. The PCR reaction mixture $(50 \mu \mathrm{l})$ consisted of SYBR Green Mix (32.5 $\mu \mathrm{l}), 1.5 \mu \mathrm{l}$ each primer (20 pmol), $12.5 \mu \mathrm{l}$ distilled water and $2 \mu \mathrm{l}$ template DNA $(0.2 \mu \mathrm{g})$. A reaction without cDNA was used as a negative control. Fluorescence quantification (\%) was achieved by calculating the ratio of the integrated optical density value of eNOS to that of GAPDH, using the $2^{-\Delta \Delta C q}$ method..

Western blot analysis. The L02 cells or middle right liver tissues of rats were lysed in lysis buffer (Genechem Co., Ltd., Shanghai, China). Lysates were centrifuged at 7,500 x $g$ for $10 \mathrm{~min}$ at $4^{\circ} \mathrm{C}$, and the supernatant was collected. Total protein levels in supernatant samples were quantified using a bicinchonic acid assay (Thermo Fisher Scientific, Inc.). Samples (50 $\mu$ g protein) underwent $10 \%$ SDS-PAGE. Proteins were then electroblotted onto a polyvinylidene difluoride membranes. The membrane was blocked with $5 \%$ fat-free milk at $4^{\circ} \mathrm{C}$ overnight, followed by incubation with rabbit eNOS primary antibody $(1: 1,000$; cat. no. MAB9028; R\&D Systems, Inc., Minneapolis, MN, USA) at $37^{\circ} \mathrm{C}$ for $2 \mathrm{~h}$. Membranes were washed three times with TBS-T, then incubated at room temperature for $1 \mathrm{~h}$ with horseradish peroxidase-conjugated secondary antibodies (1:2,000; cat. no. sc-2065; Santa Cruz Biotechnology, Inc., Dallas, TX, USA). The density of the corresponding bands was measured quantitatively using Image-Pro Plus software, version 6.0 (Media Cybernetics, Inc., Rockville, MD, USA) and corrected by reference to the value for GAPDH (1:1,000; cat. no. NB300-221; R\&D Systems, Inc.).

Cell cycle analysis. The cultured L02 cells $\left(5 \times 10^{5}\right.$ cells each group) or cell suspensions from homogenized middle left liver tissues were fixed in ice-cold $70 \%$ ethanol and centrifuged to collect a cell pellet that was resuspended in phosphate-buffered saline (PBS). After washing, cells were incubated with RNAase (Sigma-Aldrich; Merck KGaA, Darmstadt, Germany) in PBS for $30 \mathrm{~min}$ at $37^{\circ} \mathrm{C}$. After further washing, pellets were resuspended in $0.5 \mathrm{ml}$ propidium iodide staining solution $(50 \mu \mathrm{m} / \mathrm{ml})$ and incubated for $30 \mathrm{~min}$ at $4^{\circ} \mathrm{C}$. After filtering through a nylon mesh (pore size, $48 \mu \mathrm{m}$ ), apoptosis was detected using a flow cytometer (FACScalibur; BD Biosciences, San Jose, CA, USA) at an excitation setting of $488 \mathrm{~nm}$.

Immunohistochemical analysis. Paraffin-embedded middle right liver tissues were cut into $5-\mu \mathrm{m}$ sections, then deparaffinized in xylene, and dehydrated in a graded series of ethanol solutions. After antigen retrieval, the sections were incubated with primary antibody against CD68 (1:1,000; cat. no. BA3638; Wuhan Boster Bio-Engineering, Ltd., Co., Wuhan, China) or tumor necrosis factor (TNF)- $\alpha(1: 1,000$; cat. no. BA0131; Wuhan Boster Bio-Engineering, Ltd., Co.) at $4^{\circ} \mathrm{C}$ overnight. After rinsing with PBS, the sections were incubated with rabbit anti-rat IgG-Biotin secondary antibody (1:1,000; cat. no. BA1005; Wuhan Boster Bio-Engineering, Ltd., Co.) for $30 \mathrm{~min}$. The reaction was visualized using 3,3'-diaminobenzidine (DAB; Sigma-Aldrich; Merck KGaA) 
staining. The sections were rinsed with water and counterstained with Mayer's hematoxylin.

Model of small-for-size liver transplantation. Small-for-size liver transplantation was performed as described by Kamada and Kalne (17), with minor modifications (Fig. 1). Briefly, the donor rats were anesthetized by intraperitoneal injection of $100 \mathrm{mg} / \mathrm{kg}$ ketamine (Henrui Medicine, Lianyungang, China). Then, they were sacrificed by cervical dislocation. The caudate, left lateral, right superior and right inferior lobes of the rat liver were resected by ligation with $5-0$ or $7-0$ silk sutures, with the median lobe spared to obtain a liver graft of $40 \%$ (range, $36-43 \%$ ) of the original liver size. The time required for graft harvesting was $44.3 \pm 3.5 \mathrm{~min}$. The harvested livers were immediately flushed through the portal vein and stored in ice-cold Ringer's lactate solution containing $10 \mathrm{U} / \mathrm{ml}$ heparin (Kelun Pharmaceutical, Chengdu, China). After the suprahepatic vena cava, portal vein and subhepatic vena cava of the recipient were clamped, the liver was removed and the donor liver was implanted by connecting the suprahepatic vena cava. The portal vein and infrahepatic vena cava were anastomosed using the cuff technique (18). The bile duct was anastomosed with an intraluminal stent. The time required for graft implantation was recorded. The transplantation procedure lasted $44.5 \pm 4.2 \mathrm{~min}$, during which time the portal vein was clamped for 14.2 $\pm 4.1 \mathrm{~min}$. All rats survived until the end of the experiment.

Experimental animals and grouping. A total of 18 male Sprague-Dawley rats (age, 8 weeks) were purchased from the Laboratory Animal Center of Soochow University (Suzhou, China). All animal care, treatments and procedures were performed according to the guidelines approved by the Chinese Association of Animal Care and the standards for animal use and care set by the Institutional Animal Care and Use Committee. Rats were randomly divided into three groups: Experimental, control or sham group ( $n=6$ per group). Rats in the experimental group were intraperitoneally injected with Ad-eNOS (4.0x $\left.10^{9} \mathrm{PFU}\right)$, whereas rats in other two groups were injected with Ad-null (4.0x10 ${ }^{9} \mathrm{PFU}$ each). After $36 \mathrm{~h}$, rats in the experimental and control groups underwent small-for-size liver transplantation. For rats in sham group, the ligaments around the liver were freed, and the abdomen was closed 40 min later without transplantation. The quantity of bile flow was evaluated after reperfusion in recipient rats. The quantity of bile was calculated every minute for a total of ten min. At $6 \mathrm{~h}$ after reperfusion, the rats in each group were sacrificed. Blood samples were collected from the inferior vena cava, and liver tissues were dissected and stored at $-80^{\circ} \mathrm{C}$ or in $10 \%$ neutral buffered formalin until further analysis.

Terminal deoxynucleotidyltransferase-biotin nick end-labeling (TUNEL) assay. Apoptosis was detected in histological sections using a commercially available TUNEL kit (Roche Applied Science, Mannheim, Germany), according to the instructions provided by the manufacturer. Briefly, after deparaffinization and hydration, sections were digested with proteinase $\mathrm{K}$ (Solarbio Science \& Technology Co., Ltd., Beijing, China) for $10 \mathrm{~min}$. Endogenous peroxidase activity was quenched with $3 \% \mathrm{H}_{2} \mathrm{O}_{2}$ for $10 \mathrm{~min}$. The slides were incubated with terminal deoxynucleotidyl transferase and digoxigenin-dUTP at $37^{\circ} \mathrm{C}$ for
$2 \mathrm{~h}$. The sections were then incubated with a biotin-conjugated rat anti-digoxin antibody (1:100; cat. no. AR0147; Wuhan Boster Bio-Engineering, Ltd., Co.) and streptavidin biotin complex (Wuhan Boster Bio-Engineering, Ltd., Co.) for $30 \mathrm{~min}$ each. After being rinsed with PBS, the slides were immersed in DAB solution. All slides were counterstained with Mayer's hematoxylin.

Determination of serum transaminase levels. Serum alanine transaminase (ALT), aspartate transaminase (AST), and lactic acid dehydrogenase (LDH) levels were measured using an automatic biochemical analyzer (AU2700; Olympus America, Hamburg, Germany).

Quantitative analysis of NO production. NO production was measured based on the enzymatic conversion of nitrate to nitrite by nitrate reductase. Aliquots of culture supernatants $(50-\mu \mathrm{l})$ or tissue homogenates were collected and mixed with $50 \mu \mathrm{l}$ Greiss reagent ( $1 \%$ sulfanilamide and $0.1 \%$ naphthylenediamine dihydrochloride in $2 \%$ phosphoric acid). The mixture was incubated for $10 \mathrm{~min}$ with shaking at room temperature, and the absorbance at $550 \mathrm{~nm}$ (A550) was measured using a microplate reader (Bio-Rad Laboratories, Inc., Hercules, CA, USA). Nitrite concentrations were determined by comparison with a standard solution of sodium nitrite in water.

Histological examination. Liver tissues of rats in each group were washed with saline solution, immersed in $10 \%$ neutral buffered formalin, embedded in paraffin, and cut into $10-\mu \mathrm{m}$ sections. Sections were then stained with hematoxylin and eosin (H\&E) and observed under a light microscope.

Statistical analysis. Statistical analysis was performed using the SPSS software package (version 16.0; SPSS, Inc., Chicago, IL, USA). Quantitative data are presented as the mean \pm standard deviation values. Data were analyzed using one-way analysis of variance to evaluate inter-group differences. $\mathrm{P}<0.05$ was considered to indicate a statistically significant difference.

\section{Results}

eNOS expression in LO2 liver cells. RT-qPCR and western blot analyses were used to evaluate the mRNA and protein expression levels of eNOS in L02 cells. L02 cells transfected with Ad-eNOS expressed an increased mRNA level of eNOS $(21.92 \pm 6.66 \%)$, which was significantly higher than levels in L02 and Ad-null-transfected L02 cells (1.58 \pm 2.42 and $2.85 \pm 1.52 \%$, respectively; $\mathrm{P}<0.05)$. Similar differences in eNOS expression were observed western blot analysis. The results from western blot showed greater eNOS protein expression in Ad-eNOS-transfected L02 cells compared with L02 and Ad-null-transfected L02 cells ( $\mathrm{P}<0.05$; Fig. 2A and B), suggesting successful transfection of L02 cells with eNOS.

Ad-eNOS transfection increased NO production and decreased liver cell apoptosis in vitro. The ALT level in the culture supernatants in the experimental group was significantly lower than that in the control group (26.26 \pm 3.78 vs. $48.42 \pm 5.31 \mathrm{U} / 1 ; \mathrm{P}<0.05)$, but was significantly higher than that in the normal group $(17.20 \pm 2.64 \mathrm{U} / \mathrm{l} ; \mathrm{P}<0.05)$. 

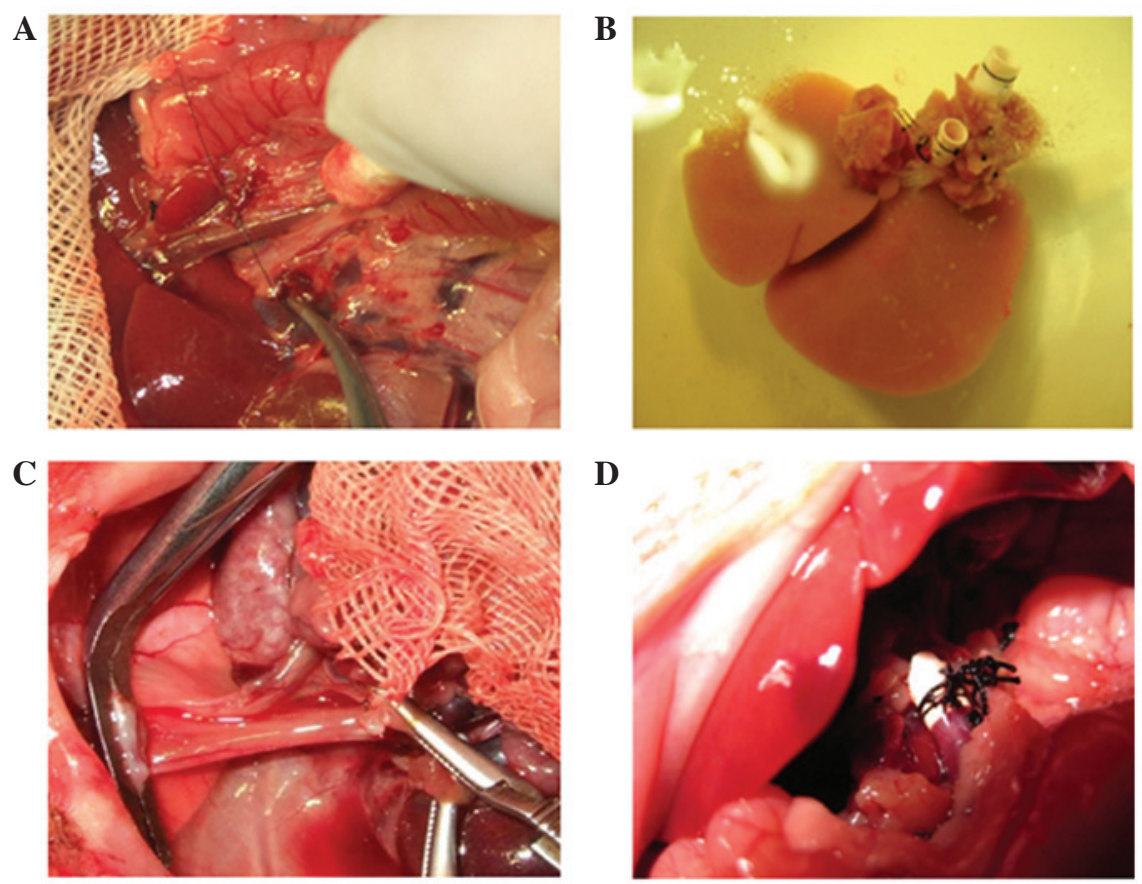

Figure 1. Rat model of small-for-size liver transplantation. (A) The portal vein was dissected and the hepatic artery ligated in the recipient rat. (B) Harvested small-for-size liver graft was stored in ice-cold preservation solution. (C) Donor liver was implanted by connecting the suprahepatic vena cava to the recipient rat. (D) After the bile duct was anastomosed with an intraluminal stent, the donor small-for-size liver graft was transplanted into the recipient rat.

Similar levels of NO products were detected in culture supernatants from the control and normal groups $(6.44 \pm 2.11 \mathrm{vs}$. $8.85 \pm 2.40 \mu \mathrm{mol} / 1$, respectively; $\mathrm{P}>0.05)$. However, the NO concentration was significantly greater in the experimental group $(18.89 \pm 3.30 \mu \mathrm{mol} / \mathrm{l})$ compared to concentrations in the control and normal groups $(\mathrm{P}<0.05)$.

To evaluate whether Ad-eNOS transfection prevented apoptosis in L02 cells, cells in each group were harvested and analyzed using flow cytometry. The rates of apoptosis in the experimental, control and normal groups were $10.10 \pm 2.91$, $20.53 \pm 2.8$ and $5.21 \pm 1.41 \%$, respectively $(\mathrm{P}<0.05$, experimental vs. control group), indicating a protective role of Ad-eNOS against apoptosis in L02 cells (Fig. 2C).

\section{Ad-eNOS transfection improved abnormal transaminase} levels following $I / R$. Rats in the control group presented reduced bile secretion and elevated levels of liver enzyme, including ALT, AST and LDH, after small-for-size liver transplantation (all $\mathrm{P}<0.05$ ). However, the quantity of bile secreted in rats in the experimental group was greater than that in rats in the control group $(\mathrm{P}<0.05)$. Rats in the experimental group exhibited deceased levels of ALT, AST and LDH $(\mathrm{P}<0.05)$, suggesting a reduction in liver tissue damage with Ad-eNOS pretreatment. A greater NO level was detected in liver tissue of rats pretreated with Ad-eNOS compared with that of rats in the control or sham groups $(\mathrm{P}<0.05$; Table I).

eNOS expression in liver tissues of rats. Rats pretreated with Ad-eNOS expressed an increased mRNA level of eNOS in liver tissues $(37.8 \pm 5.5 \%)$, which was significantly higher than levels in the control and sham groups $(16.8 \pm 6.6$ and $13.2 \pm 6.2 \%$, respectively; $\mathrm{P}<0.05$ ). Similar differences were also observed in the western blot analysis, which revealed greater protein expression of eNOS in the liver tissues of rats pretreated with Ad-eNOS (Fig. 3A and B).

Ad-eNOS treatment inhibited apoptosis in liver tissues after small-for-size liver transplantation. Rats in the control group displayed significantly more TUNEL-positive apoptotic cells in liver tissues compared with sham-operated rats (Fig. 4A). However, pretreatment with eNOS decreased the number of TUNEL-positive apoptotic cells in liver tissues. These results are consistent with the results of the flow cytometry analysis, which revealed a reduced percentage of apoptotic cells in liver tissues of rats pretreated with eNOS $(3.9 \pm 0.9$ vs. $11.8 \pm 1.3 \%$ in the control group; $\mathrm{P}<0.05$ ), although this value remained higher than that in the sham group $(1.2 \pm 0.4 \%$, $\mathrm{P}<0.05$; Fig. 4B).

Ad-eNOS treatment restored histological changes in liver tissues after small-for-size liver transplantation. To assess the protective effects of eNOS on liver tissues, histological analysis by $\mathrm{H} \& \mathrm{E}$ staining was performed at $6 \mathrm{~h}$ after reperfusion. Control liver sections showed swelling and redness of liver tissues, with severe endothelial cell damage and massive inflammatory cell infiltration surrounding the periportal region (Fig. 5A). However, there was a significant improvement in the liver histological abnormalities in Ad-eNOS-pretreated rats, which showed normal hepatocyte morphology, complete vascular walls, and reduced inflammatory cell infiltration in the periportal region.

The number of TNF- $\alpha$-positive cells in liver tissues was reduced in Ad-eNOS-pretreated rats compared with the Ad-null-pretreated rats (control) after small-for-size liver transplantation (Fig. 5B). Similarly, the rats pretreated with Ad-eNOS showed significantly fewer CD68-positive 
Table I. Effects of overexpression of eNOS on bile secretion, NO concentration and liver enzyme levels in rats (n=6 per group).

\begin{tabular}{lccc}
\hline Parameters & Sham group & Control group & Experimental group \\
\hline Bile secretion $\left(\mathrm{mm}^{3} / 10 \mathrm{~min}\right)$ & $92.5 \pm 12.2$ & $29.8 \pm 3.8^{\mathrm{a}}$ & $62.3 \pm 8.7^{\mathrm{a}, \mathrm{b}}$ \\
NO concentration $(\mu \mathrm{mol} / \mathrm{l})$ & $18.9 \pm 6.2$ & $23.9 \pm 4.1$ & $57.9 \pm 8.0^{\mathrm{a}, \mathrm{b}}$ \\
ALT (U/l) & $20.3 \pm 15.0$ & $1,947.3 \pm 373.0^{\mathrm{a}}$ & $636.4 \pm 69.1^{\mathrm{a}, \mathrm{b}}$ \\
AST (U/l) & $32.4 \pm 13.8$ & $2,415.7 \pm 259.9^{\mathrm{a}}$ & $1,163.2 \pm 252.2^{\mathrm{a}, \mathrm{b}}$ \\
LDH (U/l) & $125.3 \pm 32.5$ & $3,836.3 \pm 518.3^{\mathrm{a}}$ & $2,364.6 \pm 211.6^{\mathrm{a}, \mathrm{b}}$ \\
\hline
\end{tabular}

${ }^{\mathrm{a}} \mathrm{P}<0.05$ vs. sham group; ${ }^{\mathrm{b}} \mathrm{P}<0.05$ vs. control group. eNOS, endothelial nitric oxide synthase; $\mathrm{NO}$, nitric oxide; ALT, alanine transaminase; AST, aspartate transaminase; $\mathrm{LDH}$, lactate dehydrogenase.

A

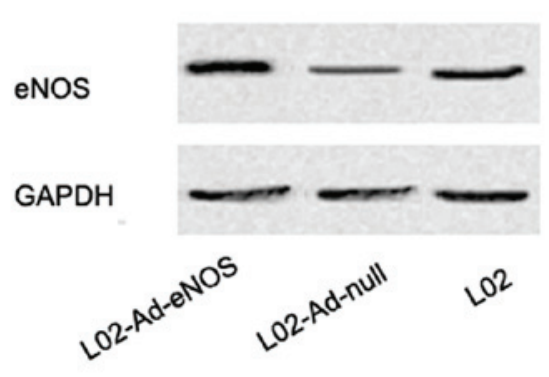

B

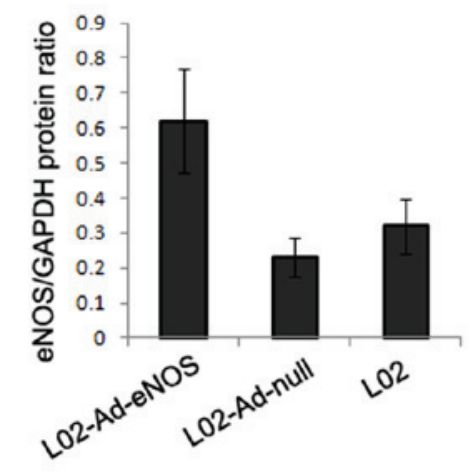

C

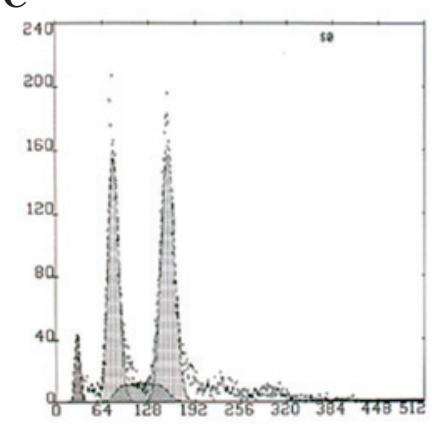

Experimental group

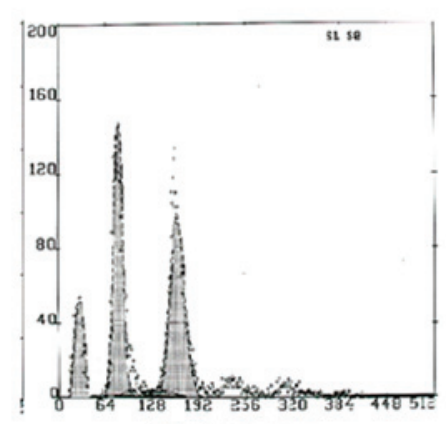

Control group

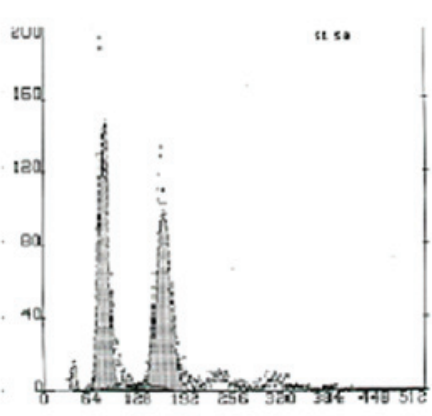

Normal group

Figure 2. In vitro experiments. (A) Western blot analysis showed increased eNOS protein expression in Ad-eNOS-transfected L02 cells, as compared with L02 cells and Ad-null-treated L02 cells. (B) Quantification of protein levels of eNOS, normalized by GAPDH expression, P $<0.05$. (C) Ad-eNOS exerted a protective effect against apoptosis in L02 cells according to flow cytometric analysis. The rates of against in the experimental, control and normal groups were $10.10 \pm 2.91,20.53 \pm 2.8$ and $5.21 \pm 1.41 \%$, respectively ( $\mathrm{P}<0.05$, experimental vs. control group). eNOS, endothelial nitric oxide synthase; Ad, adinovirus.

A

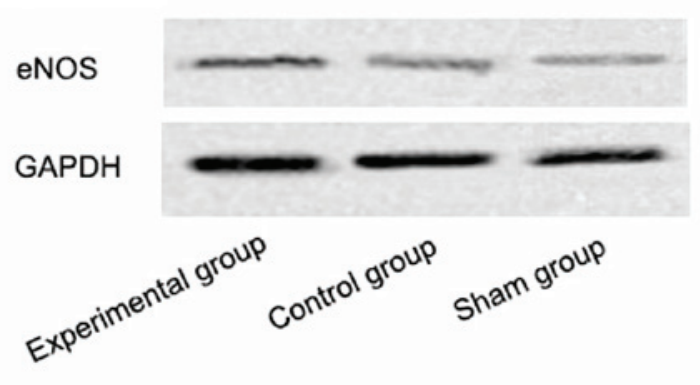

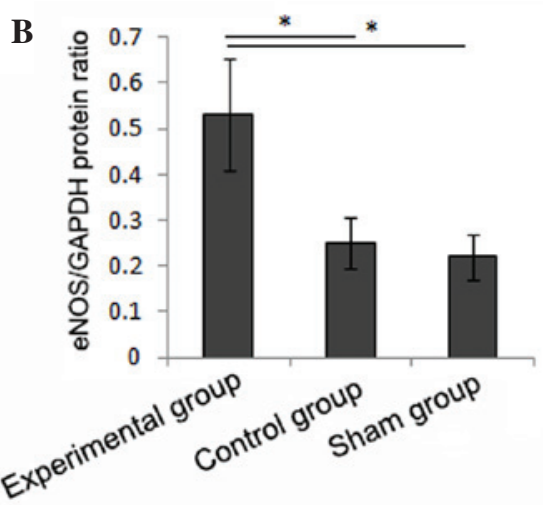

Figure 3. (A) Western blot analysis revealed increased eNOS protein expression in liver tissues of rats pretreated with Adenovirus-eNOS. (B) Quantification of eNOS protein levels normalized against GAPDH levels. "P<0.05. eNOS, endothelial nitric oxide synthase. 
A

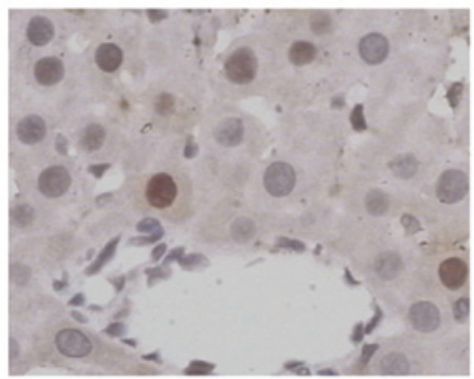

Experimental group

B

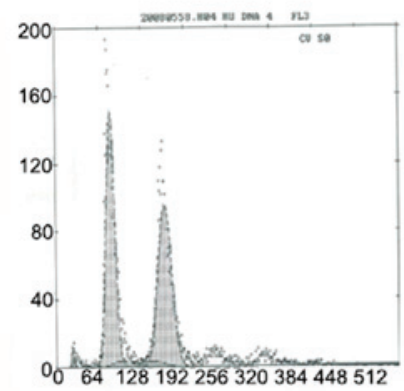

Experimental group

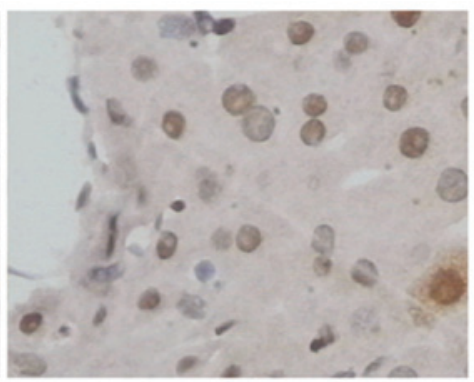

Control group

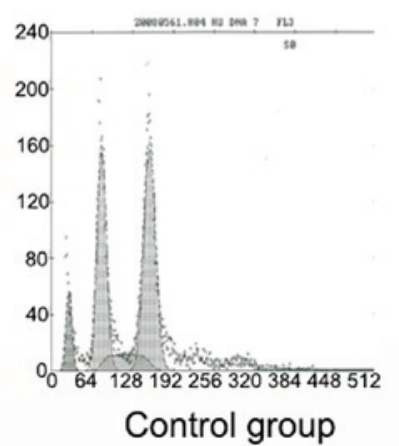

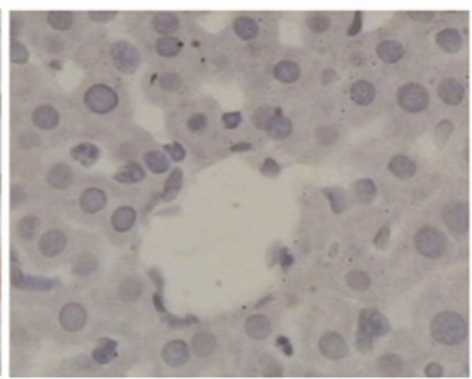

Sham group

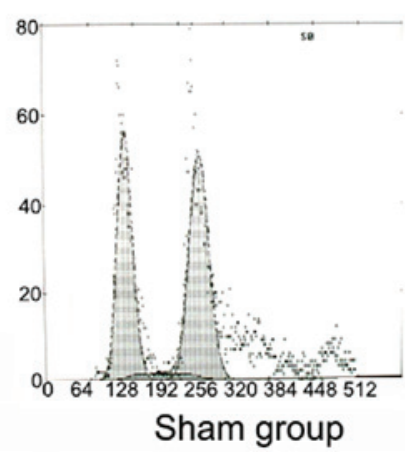

Figure 4. Adenovirus-endothelial nitric oxide synthase (Ad-eNOS) inhibited apoptosis in liver tissues after small-for-size liver transplantation. Rats in the experimental group were intraperitoneally injected with Ad-eNOS (4.0x109 PFU), whereas rats in the control and sham groups were injected with Ad-null (4.0x $10^{9} \mathrm{PFU}$ each). After $36 \mathrm{~h}$, rats in the experimental and control groups underwent small-for-size liver transplantation. (A) Rats pretreated with Ad-eNOS displayed significantly fewer TUNEL-positive apoptotic cells in liver tissues at $6 \mathrm{~h}$ after ischemic/reperfusion (I/R; magnification, $\mathrm{x} 400$ ). (B) Flow cytometric

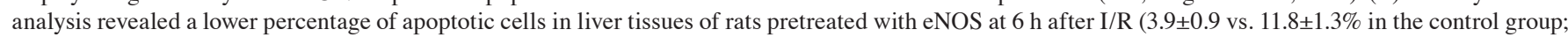
$\mathrm{P}<0.05)$, although this number was still higher than that in the sham group $(1.2 \pm 0.4 \% ; \mathrm{P}<0.05)$.

immunoreactive macrophages in vascular walls at $6 \mathrm{~h}$ after reperfusion than compared with the control group (Fig. 5C).

\section{Discussion}

I/R injury, caused by cold ischemia during organ storage and subsequent reperfusion, may inevitably occur during small-for-size liver transplantation, resulting in delayed graft function and decreased long-term graft survival (19). In the present study, in vivo experimental studies showed that Ad-eNOS pretreatment significantly increased bile production, improved abnormal transaminase levels, diminished apoptotic liver cells and decreased hepatocellular damage. These findings suggested that eNOS-mediated NO production plays a crucial role in the protection of hepatocytes against I/R injury following small-for-size liver transplantation. The eNOS-mediated renal protective effects may associate with downregulation of TNF- $\alpha$ and a reduction in macrophage activation during the early stage of reperfusion in small-for-size liver allografts.

Previous experiments suggests that NO functions as a protective factor during I/R injury (20). It has been reported that endogenous NO produced by eNOS or activation of NOS may protect liver cells from I/R injury (21). Furthermore, the delivery of exogenous NO during an ischemic insult has been shown to limit the extent of reperfusion damage, suggesting a beneficial role of NO against I/R injury following organ transplantation $(22,23)$. Moreover, administration of L-arginine or FK409 (potent spontaneous NO releasers) into the hepatic vasculature results in improved hepatic tissue blood flow, serum liver enzyme levels, and well-preserved endothelial cells, thereby enhancing graft survival following I/R (24-26). In the present study, we detected an increased NO concentration in culture supernatants of L02 cells pretreated with Ad-eNOS. In addition, the NO level was greater in the liver tissue of rats pretreated with Ad-eNOS as compared with the level in control rats $(\mathrm{P}<0.05)$. Histological findings revealed severe endothelial cell damage and massive inflammatory cell infiltration surrounding the periportal region in Ad-null-pretreated rats following I/R. By contrast, in the Ad-eNOS-pretreated rats there was a significant improvement in histological abnormalities in the liver, with normal hepatocyte morphology, complete vascular walls and reduced inflammatory cell infiltration in the periportal region. Thus, we propose that Ad-eNOS-mediated $\mathrm{NO}$ may be responsible for the renal protective effect against I/R injury following small-for-size liver transplantation. The exact mechanism by which eNOS exerts its protective effects via NO requires further investigation.

The protective effect of eNOS against I/R injury following organ transplantation has been investigated by directly altering eNOS expression in several studies $(26,27)$. It has been reported that eNOS overexpression can lead to reduced infarct size after cardiac I/R injury $(27,28)$. A study performed by Duranski et al showed that transgenic mice with eNOS overexpression exhibit less severe I/R injury than wild-type mice, and this hepatoprotective effect was probably mediated through the soluble guanylyl cyclase-cGMP pathway independent of heme oxygenase-1 (29). By contrast, liver injury is more severe in eNOS-deficient mice subjected to liver I/R injury than in wild-type counterparts (30). In a murine liver 

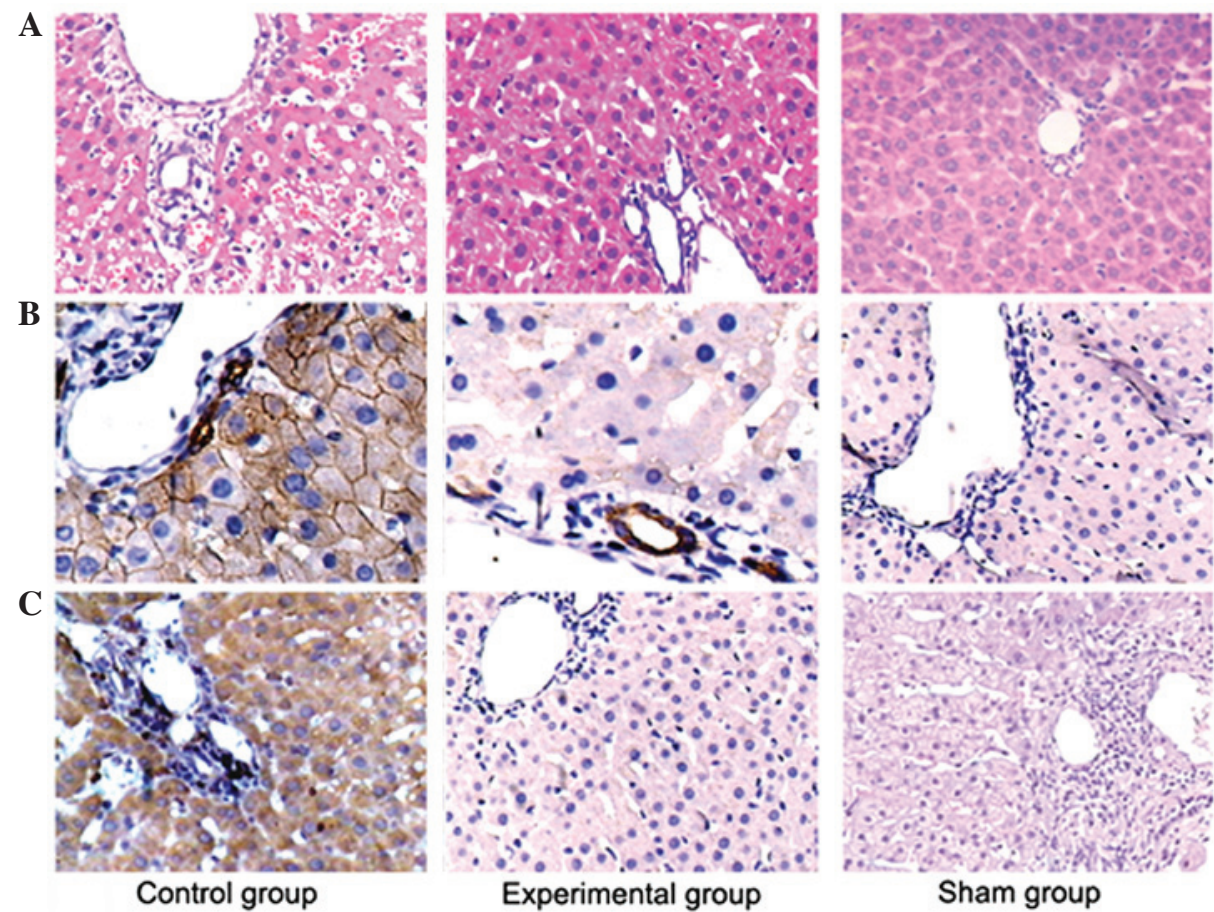

Figure 5. Histological findings. (A) Adenovirus-endothelial nitric oxide synthase (Ad-eNOS)-pretreated rats exhibited improvement in liver histological abnormalities, with normal hepatocyte morphology, complete vascular walls and reduced inflammatory cell infiltration in the periportal region at $6 \mathrm{~h}$ after ischemia/reperfusion (I/R), as compared to controls (magnification, $x 200$ ). (B) Immunohistochemical staining showed fewer tumor necrosis factor- $\alpha$-positive cells in liver tissues of Ad-eNOS-pretreated rats than in Ad-null-pretreated rats at $6 \mathrm{~h}$ after I/R (magnification, x200). (C) Rats pretreated with Ad-eNOS showed significantly fewer CD68-positive immunoreactive macrophages in vascular walls at $6 \mathrm{~h}$ after reperfusion than the control group (magnification, $\mathrm{x} 200$ ).

transplant model from eNOS-deficient donor to wild-type mice, eNOS-deficient grafts resulted in greater I/R injury, increased microcirculatory disturbances and increased macrophage infiltration (31). However, the dual role for eNOS in hepatic I/R injury remains controversial. An animal study by Palanisamy et al showed that adenovirus-mediated eNOS overexpression is detrimental to the mouse liver during I/R, leading to elevated AST and ALT levels and significantly increased apoptosis at $24 \mathrm{~h}$ after reperfusion (32). In the present study, eNOS overexpression significantly attenuated hepatic I/R injury in Ad-eNOS-infected mouse livers, as evidenced by the correction of increased transaminase levels and improvement in histological signs of liver damage following small-for-size liver transplantation. The present results are consistent with the findings of Duranski et al, which suggested that genetic overexpression of eNOS protected against hepatic I/R injury in vivo following $5 \mathrm{~h}$ of reperfusion (29).

Apoptosis has been identified as a key mechanism underlying hepatic I/R injury. Reperfusion of livers after cold ischemia during organ storage results in endothelial cell adhesion, microcirculatory disturbances, activation of Kupffer cells, and concomitantly, the release of ROS and proinflammatory cytokines such as TNF- $\alpha$, thereby promoting hepatocellular apoptosis after liver transplantation (33). A previous study found increased numbers of apoptotic and necrotic cells in small-for-size grafts vs. whole grafts after liver transplantation in rats (34). Therefore, inhibition of apoptosis may provide protection for liver grafts against I/R injury, particularly for small-for-size grafts. In the present study, rats pretreated with Ad-eNOS displayed significantly fewer TUNEL-positive apoptotic cells in liver tissues in comparison with rats pretreated with Ad-null, and this result is consistent with the findings from the flow cytometric analysis. Thus, we speculate that overexpression of eNOS using an adenoviral vector resulted in sustained NO production and protection of hepatocytes from apoptosis in both in vitro and in vivo experiments.

TNF- $\alpha$ is a cytokine produced by numerous cell types in response to inflammatory stimuli (35). TNF- $\alpha$ serves a crucial function in hepatocyte injury during I/R, and the mechanisms are complex ,with interactions involving ROS, NO, adhesion molecules and various cytokines and chemokines (36). It has been reported that proinflammatory cytokines, such as TNF- $\alpha$, interleukin (IL)-1 and IL-6, are observed in acute lung injury following orthotopic liver transplantation at $4 \mathrm{~h}$ after reperfusion (37). In the present study, a significant reduction in the number of TNF- $\alpha$-positive cells at $6 \mathrm{~h}$ after reperfusion was observed in liver tissues of Ad-eNOS-pretreated rats in comparison with control counterparts. These results were consistent with those of a previous study showing that ischemic preconditioning is responsible for a protective effect on liver morphology and associated with a decrease in the serum TNF- $\alpha$ level (38). In addition, early activation of macrophages also accelerates an early immune process following graft I/R injury in small-for-size allografts (39). In the present study, rats pretreated with Ad-eNOS showed significantly fewer CD68-positive immunoreactive macrophages in vascular walls, suggesting Ad-eNOS may inhibit the inflammatory process by decreasing early activation of macrophages in small-for-size allografts. These effects may contribute to the eNOS-mediated hepatic protection following I/R.

In conclusion, the present results indicate that eNOS-derived NO production significantly attenuates hepatic I/R injury. Thus, 
eNOS overexpression may constitute a promising therapeutic approach to prevent liver I/R injury following small-for-size liver transplantation.

\section{Acknowledgements}

The present study was supported by the Science and Technology Development Plan of Soochow (grant no. SYSD2014012).

\section{References}

1. Li KK and Neuberger J: The management of patients awaiting liver transplantation. Nat Rev Gastroenterol Hepatol 6: 648-659, 2009.

2. Ma T, Liu H, Chen W, Xia X, Bai X, Liang L, Zhang Y and Liang T: Implanted adipose-derived stem cells attenuate small-for-size liver graft injury by secretion of VEGF in rats. Am J Transplant 12: 620-629, 2012.

3. Park GC, Song GW, Moon DB and Lee SG: A review of current status of living donor liver transplantation. Hepatobiliary Surg Nutr 5: 107-117, 2016

4. Wang HS, Ohkohchi N, Enomoto Y, Usuda M, Miyagi S, Asakura T, Masuoka H, Aiso T, Fukushima K, Narita T, et al: Excessive portal flow causes graft failure in extremely small-for-size liver transplantation in pigs. World J Gastroenterol 11: 6954-6959, 2005.

5. Yamada N, Sanada Y, Hirata Y, Okada N, Ihara Y, Sasanuma H, Urahashi T, Sakuma Y, Yasuda Y and Mizuta K: The outcomes of pediatric living donor liver transplantation using small-for-size grafts: Experience of a single institute. Pediatr Surg Int 32: 363-368, 2016.

6. Wang W, Du Z, Yan J, Ma D, Shi M, Zhang M, Peng C and Li H: Mesenchymal stem cells promote liver regeneration and prolong survival in small-for-size liver grafts: Involvement of C-Jun N-terminal kinase, cyclin D1 and NF-кB. PLoS One 9: e112532, 2014.

7. Carini R and Albano E: Recent insights on the mechanisms of liver preconditioning. Gastroenterology 125: 1480-1491, 2003.

8. Weigand K, Brost S, Steinebrunner N, Büchler M, Schemmer P and Müller M. Ischemia/reperfusion injury in liver surgery and transplantation: pathophysiology. HPB Surg 2012: 176723, 2012.

9. Kalogeris T, Baines CP, Krenz M and Korthuis RJ: Cell biology of ischemia/reperfusion injury. Int Rev Cell Mol Biol 298: 229-317, 2012.

10. Choukér A, Martignoni A, Schauer RJ, Dugas M, Schachtner T, Kaufmann I, Setzer F, Rau HG, Löhe F, Jauch KW, et al: Alpha-gluthathione S-transferase as an early marker of hepatic ischemia/reperfusion injury after liver resection. World J Surg 29: 528-534, 2005.

11. Selzner N, Rudiger H, Graf R and Clavien PA: Protective strategies against ischemic injury of the liver. Gastroenterology 125: 917-936, 2003.

12. Iñiguez M, Dotor J, Feijoo E, Goñi S, Prieto J, Berasain C and Avila MA: Novel pharmacologic strategies to protect the liver from ischemia-reperfusion injury. Recent Pat Cardiovasc Drug Discov 3 : 9-18, 2008.

13. Han KH, Jung JY, Chung KY, Kim H and Kim J: Nitric oxide synthesis in the adult and developing kidney. Electrolyte Blood Press 4: 1-7, 2006.

14. Lundberg JO and Weitzberg E: NO-synthase independent NO generation in mammals. Biochem Biophys Res Commun 396: $39-45,2010$

15. Mukhopadhyay $P$, Rajesh M, Horváth $B$, Bátkai S, Park $O$, Tanchian G, Gao RY,Patel V, Wink DA, Liaudet L, et al: Cannabidiol protects against hepatic ischemia/reperfusion injury by attenuating inflammatory signaling and response, oxidative/nitrative stress, and cell death. Free Radic Biol Med 50: 1368-1381, 2011

16. Siriussawakul A, Zaky A and Lang JD: Role of nitric oxide in hepatic ischemia-reperfusion injury. World J Gastroenterol 16: 6079-6086, 2010

17. Kamada N and Calne RY: A surgical experience with five hundred thirty liver transplants in the rat. Surgery 93: 64-69, 1983.

18. Tan F, Chen Z, Zhao Y, Liang T, Li J and Wei J: Novel technique for suprahepatic vena cava reconstruction in rat orthotopic liver transplantation. Microsurgery 25: 556-560, 2005.

19. Gueler F, Gwinner W, Schwarz A and Haller H. Long-term effects of acute ischemia and reperfusion injury. Kidney Int 66: 523-527, 2004
20. Shimamura T, Zhu Y, Zhang S, Jin MB, Ishizaki N, Urakami A, Totsuka E, Kishida A, Lee R, Subbotin V, et al: Protective role of nitric oxide in ischemia and reperfusion injury of the liver. J Am Coll Surg 188: 43-52, 1999.

21. Grossini E, Pollesello P, Bellofatto K, Sigaudo L, Farruggio S, Origlia V, Mombello C, Mary DA, Valente G and Vacca G: Protective effects elicited by levosimendan against liver ischemia/reperfusion injury in anesthetized rats. Liver Transpl 20: 361-375, 2014

22. Phillips L, Toledo AH, Lopez-Neblina F, Anaya-Prado R and Toledo-Pereyra LH: Nitric oxide mechanism of protection in ischemia and reperfusion injury. J Invest Surg 22: 46-55, 2009.

23. Lang JD Jr, Teng X, Chumley $\mathrm{P}$, Crawford JH, Isbell TS, Chacko BK, Liu Y, Jhala N, Crowe DR, Smith AB, et al: Inhaled $\mathrm{NO}$ accelerates restoration of liver function in adults following orthotopic liver transplantation. J Clin Invest 117: 2583-2591, 2007.

24. Aiba M, Takeyoshi I, Ohwada S, Kawashima Y, Iwanami K, Sunose Y, Yamada T, Tsutsumi H, Matsumoto K and Morishita Y: Novel nitric oxide donor (FK409) ameliorates liver damage during extended liver resection with warm ischemia in dogs. J Am Coll Surg 193: 264-271, 2001.

25. Li SQ and Liang LJ: Protective mechanism of L-arginine against liver ischemic-reperfusion injury in rats. Hepatobiliary Pancreat Dis Int 2: 549-552, 2003

26. Trocha M, Merwid-Lad A, Szuba A, Chlebda E, Pieśniewska M, Sozański T and Szelag A: Effect of simvastatin on nitric oxide synthases (eNOS, iNOS) and arginine and its derivatives (ADMA, SDMA) in ischemia/reperfusion injury in rat liver. Pharmacol Rep 62: 343-351, 2010

27. Jones SP, Greer JJ, Kakkar AK, Ware PD, Turnage RH, Hicks M, van Haperen R, de Crom R, Kawashima S, Yokoyama M and Lefer DJ: Endothelial nitric oxide synthase overexpression attenuates myocardial reperfusion injury. Am J Physiol Heart Circ Physiol 286: H276-H282, 2004.

28. Ghavami S, Hashemi M, Kadkhoda K, Alavian SM, Bay GH and Los M: Apoptosis in liver diseases - detection and therapeutic applications. Med Sci Monit 11: RA337-RA345, 2005.

29. Duranski MR, Elrod JW, Calvert JW, Bryan NS, Feelisch M and Lefer DJ: Genetic overexpression of eNOS attenuates hepatic ischemia-reperfusion injury. Am J Physiol Heart Circ Physiol 291: H2980-H2986, 2006.

30. Abu-Amara M, Yang SY, Quaglia A, Rowley P, Fuller B, Seifalian A and Davidson B: Role of endothelial nitric oxide synthase in remote ischemic preconditioning of the mouse liver. Liver Transpl 17: 610-619, 2011.

31. Theruvath TP, Zhong Z, Currin RT, Ramshesh VK and Lemasters JJ: Endothelial nitric oxide synthase protects transplanted mouse livers against storage/reperfusion injury: Role of vasodilatory and innate immunity pathways. Transplant Proc 38: 3351-3357, 2006.

32. Palanisamy AP, Cheng G, Sutter AG, Liu J, Lewin DN, Chao J and Chavin K: Adenovirus-mediated eNOS expression augments liver injury after ischemia/reperfusion in mice. PLoS One 9: e93304, 2014.

33. Mendes-Braz M, Elias-Miró M, Jimenez-Castro MB, Casillas-Ramírez A, Ramalho FS and Peralta C: The current state of knowledge of hepatic ischemia-reperfusion injury based on its study in experimental models. J Biomed Biotechnol 2012: 298657, 2012.

34. Liang TB, Man K, Kin-Wah Lee T, Hong-Teng Tsui S, Lo CM, $\mathrm{Xu}$ X, Zheng SS, Fan ST and Wong J: Distinct intragraft response pattern in relation to graft size in liver transplantation. Transplantation 75: 673-678, 2003.

35. Perry BC, Soltys D, Toledo AH and Toledo-Pereyra LH: Tumor necrosis factor- $\alpha$ in liver ischemia/reperfusion injury. J Invest Surg 24: 178-188, 2011.

36. Perry BC, Soltys D, Toledo AH and Toledo-Pereyra LH: Tumor necrosis factor- $\alpha$ in liver ischemia/reperfusion injury. J Invest Surg 24: 178-188, 2011

37. Zhang A, Chi X, Luo G, Hei Z, Xia H, Luo C, Wang Y, Mao X and Xia Z: Mast cell stabilization alleviates acute lung injury after orthotopic autologous liver transplantation in rats by downregulating inflammation. PLoS One 8: e75262, 2013.

38. Czigány Z, Turóczi Z, Ónody P, Harsányi L, Lotz G, Hegedüs V and Szijártó A: Remote ischemic perconditioning protects the liver from ischemia-reperfusion injury. J Surg Res 185: 605-613, 2013.

39. Yang ZF, Ho DW, Chu AC, Wang YQ and Fan ST: Linking inflammation to acute rejection in small-for-size liver allografts: The potential role of early macrophage activation. Am J Transplant 4: 196-209, 2004 